\title{
PENINGKATAN KINERJA BADAN USAHA MILIK DESA MELALUI PENDAMPINGAN DALAM MANAJEMEN KEUANGAN
}

\author{
Azwar Annas'), lid Mufaidah"), Dimas Juli Prasetyo1) \\ 1) Program Studi Agribisnis, Institut Teknologi dan Bisnis Muhammadiyah Banyuwangi, Banyuwangi, Jawa Timur, \\ Indonesia \\ Corresponding author : Azwar Annas \\ E-mail : azwar.ann@itbmb.ac.id
}

Diterima 08 Juli 2021, Disetujui 03 Agustus 2021

\begin{abstract}
ABSTRAK
Badan Usaha Milik Desa (BUMDes) Lembu Suro, Desa Genteng Kulon, Kabupaten Banyuwangi, Jawa Timur merupakan badan usaha yang bergerak dalam bidang usaha properti desa yang siap untuk disewakan kepada masyarakat pelaku usaha di Desa Genteng Kulon. Laporan keuangan BUMDes Lembu Suro biasa dilaporkan setiap tahun kepada Kepala Desa dan Badan Permusyawaratan Desa. Namun, kondisi manajemen keuangan BUMDes cukup buruk dengan catatan yang tidak teratur sehingga laporan keuangan tersebut cukup sulit dibaca. Kegiatan pengabdian masyarakat dari Agribisnis Institut Tekonologi dan Bisnis Muhammadiyah Banyuwangi adalah meningkatkan kinerja keuangan BUMDes dengan melakukan audit keuangan untuk melihat pencatatan keuangan BUMDes Lembu Suro sekaligus untuk menemukan kelemahannya sehingga bisa menjadi referensi peningkatan kinerja laporan keuangan BUMDes. Pengabdian masyarakat ini dilakukan dengan metode pengamatan langsung dan diskusi mendalam. Hasil kegiatan ini menunjukkan bahwa pencatatan keuangan sudah dilakukan secara terperinci dan tidak ada kesalahan atau kecurangan. Beberapa kelemahan yang ditemukan yaitu kurangnya kerapian, tidak mempunyai jurnal umum, tidak mempunyai buku besar, penamaan unit yang tidak konsisten, dan transaksi pengeluaran yang tidak detail.
\end{abstract}

Kata kunci: BUMDes, audit, pembukuan

\begin{abstract}
The Village Owned Enterprise (BUMDes) Lembu Suro, Genteng Kulon Village, Banyuwangi Regency, East Java is a business entity engaged in the village property business that is ready to be rented out to the business community in Genteng Kulon Village. Lembu Suro BUMDes financial reports are usually reported annually to the Village Head and the Village Consultative Body. However, the condition of BUMDes financial management is quite bad with irregular records so that the financial statements are quite difficult to read. The community service activity of the Agribusiness Institute of Technology and Business of Muhammadiyah Banyuwangi is to improve the financial performance of BUMDes by conducting a financial audit to see the financial records of BUMDes Lembu Suro as well as to find weaknesses so that it can be a reference for improving the performance of BUMDes financial statements. This community service is carried out by direct observation and in-depth discussion methods. The results of this activity indicate that the financial records have been carried out in detail and there are no errors or fraud. Some of the weaknesses found were lack of neatness, not having a general journal, not having a general ledger, inconsistent unit naming, and expense transactions that were not detailed.
\end{abstract}

Keywords: BUMDes; audit; bookkeeping.

\section{PENDAHULUAN}

Indonesia memiliki potensi yang sangat besar dari usaha mikro kecil menengah (UMKM) yang tersebar di berbagai wilayah. Dalam data Kemenkopukm (2021), potensi UMKM di Indonesia tergolong sangat besar karena jumlah UMKM mencapai lebih dari 64 juta. Jumlah tersebut sangat besar jika dibandingkan dengan jumlah perusahaan besar. Persentase jumlah UMKM dari seluruh usaha yaitu sebesar 99,99 persen dengan kemampuan penyerapan tenaga kerja sebesar 97 persen (Kemenkopukm, 2021). Perusahaan besar hanya memiliki pangsa pasar sebesar 0,01 persen. Hal ini menegaskan bahwa setiap UMKM mempunyai peran yang penting dalam perekonomian Indonesia. Selain itu, suatu perubahan kondisi nasional akan mempengaruhi UMKM secara luas.

Pada tahun 2020 merupakan awal pandemi covid-19 yang mempengaruhi perekonomian di seluruh Indonesia. Hal ini 
sangat dirasakan oleh UMKM di seluruh Indonesia dan mempengaruhi penurunan kondisi perekonomian nasional (Nainggolan, 2020). Badan Usaha Milik Desa (BUMDes) merupakan salah satu jenis UMKM yang terdampak oleh pandemi. Bentuk usaha BUMDes ini merupakan unit usaha yang dimiliki oleh sebuah desa. Badan usaha sejenis BUMDes ini bisa menjadi pendorong kegiatan usaha di masyarakat dengan berbagai fasilitasnya yang didukung oleh pemerintahan desa. Bahkan, menurut Asti dan Cholid (2018), mayoritas masyarakat desa telah memperoleh manfaat dari keberadaan BUMDes sekitar 82 persen. Selain itu, menurut Kementerian Desa, Pembangunan Daerah Tertinggal dan Transmigrasi Republik Indonesia (Kemendes 2021), BUMDes akan menjadi kunci pemulihan ekonomi nasional pada masa pasca pandemi covid-19.

Badan Usaha Milik Desa (BUMDes) Lembu Suro, Desa Genteng Kulon, Kabupaten Banyuwangi, Provinsi Jawa Timur adalah salah satu BUMDes yang melakukan kerja sama dengan Program Studi (Prodi) Agribisnis, Institut Teknologi dan Bisnis Muhammadiyah Banyuwangi. Kerjasama yang dilakukan adalah upaya meningkatkan kinerja bisnis bagi BUMDes. Lembaga tersebut merupakan aset penting bagi Desa Genteng Kulon sebagai salah satu bentuk penyangga ekonomi dalam lingkup desa. Pemerintah Desa mempunyai BUMDes untuk mengelola berbagai aset milik desa, juga sebagai fasilitas masyarakat untuk mengembangkan usaha bersama.

Lembaga BUMDes Lembu Suro, pada saat ini menjadi harapan yang sangat besar untuk pemulihan ekonomi di tingkat Desa Genteng Kulon yang memburuk akibat pandemi covid-19. Seperti di dalam Ibrahim dkk (2018), Ibrahim dan Sutarna (2018), bahwa keberadaan BUMDes bisa sangat membantu meningkatkan kesejahteraan masyarakat pedesaan melalui berbagai pelayanan dan unit usahanya. Akan tetapi, kondisi saat ini menunjukkan bahwa kinerja BUMDes Lembu Suro belum optimal. Kondisi tersebut dirasakan oleh pemerintah desa Genteng Kulon sejak sebelum pandemi covid-19 meluas. Oleh karena itu, perlu dilakukan pendampingan dari pihak setara universitas sekaligus sebagai bentuk pengabdian kepada masyarakat.

BUMDes Lembu Suro dari Desa Genteng Kulon masih mengalami berbagai masalah manajemen. Salah satu manajemen yang paling lemah adalah tentang keuangan. Manajemen keuangan tentunya membutuhkan pencatatan yang baik. Hal tersebut untuk mempermudah pengecekan bagi para pengurus juga sebagai pertanggung jawaban kepada pemerintah desa. Selain itu, transparansi keuangan BUMDes penting untuk diketahui masyarakat karena di dalam BUMDes juga terdapat aliran penggunaan dana desa (Irawati dan Martanti, 2017). Pencatatan keuangan BUMDes Lembu Suro saat ini tergolong lemah karena menggunakan cara yang semaunya dan kurang teratur. Hal tersebut membuat lembaga pengawas keuangan desa kurang dapat memahami pencatatan yang dilakukan BUMDes.

Pengabdian masyarakat yang dilakukan oleh Prodi Agribisnis adalah untuk meningkatkan kinerja keuangan BUMDes Lembu Suro dengan cara memberikan audit keuangan sebagai bentuk kegiatan pengawasan keuangan dari pihak eksternal BUMDes Lembu Suro sekaligus untuk menemukan kekurangan dari pencatatan keuangan tersebut. Hasil dari pengabdian masyarakat ini adalah sebuah informasi tentang keadaan keuangan dan rincian kekurangan dari pencatatan keuangan yang dilakukan oleh BUMDes sehingga dapat dilakukan kegiatan perbaikan.

\section{METODE}

Pengabdian masyarakat ini dilaksanakan dengan metode pengamatan langsung terhadap dokumen pembukuan milik BUMDes Lembu Suro. Adapun rincian kegiatan tersebut adalah sebagai berikut:

1. Penerimaan pihak kampus ITBM Banyuwangi oleh Kepala Desa Genteng Kulon dan Direktur BUMDes Lembu Suro.

2. Kegiatan audit keuangan dilakukan dengan menerima seluruh catatan dan dokumen keuangan.

3. Diskusi mendalam dengan seluruh pengurus BUMDes terkait pencatatan dan pembukuan dengan pengurus BUMDes pada saat proses audit.

4. Sosialisasi hasil temuan dari proses audit dan potensi pengembangan pembukuan BUMDes Lembu Suro, kepada jajaran pengurus yang terkait.

5. Penyampaian materi singkat tentang pembukuan yang baik, berdasarkan temuan kelemahan sistem pembukuan keuangan BUMDes Lembu Suro.

\section{HASIL DAN PEMBAHASAN}

Kerjasama Prodi Agribisnis dengan Desa Genteng Kulon adalah kerjasama untuk mengembangkan perekonomian masyarakat Desa Genteng Kulon. Salah satu kegiatan yang pertama kali dilakukan setelah melakukan kerjasama adalah peningkatan kinerja BUMDes Lembu Suro yang merupakan BUMDes Desa 
Genteng Kulon. BUMDes tersebut memiliki usaha dalam pengelolaan aset desa. Usaha tersebut lebih kepada usaha properti yaitu penyewaan lahan usaha dan tempat parkir.

Kegiatan peningkatan kinerja BUMDes Lembu Suro dilakukan dengan kegiatan awal yaitu diskusi mendalam dengan pihak manajemen terkait kondisi BUMDes (Gambar 1). Kondisi BUMDes Lembu Suro pada saat ini didapatkan telah mengalami penurunan pemasukan yang cukup signifikan akibat pandemi mulai dari bulan Maret tahun 2020. Pada awal Maret 2021, BUMDes Lembu Suro mulai bangkit kembali karena usaha properti yang disewakan mulai digunakan kembali. Disamping itu, BUMDes harus melaporkan kondisi keuangan selama tahun 2020 meskipun mengalami kondisi transaksi minimal pada tahun 2020. Menurut Irawati dan Martanti (2017), laporan keuangan BUMDes diperlukan untuk semua elemen masyarakat sebagai bentuk pertanggung jawaban serta sebagai bahan pertimbangan untuk pengambilan keputusan selanjutnya. Menurut Kepala Desa Genteng Kulon, kegiatan laporan keuangan tersebut membutuhkan audit eksternal untuk meningkatkan kinerja pengawasan keuangan BUMDes. Hal tersebut menjadi kegiatan pengabdian masyarakat pertama bagi kerjasama antara Desa Genteng Kulon dan ITBM Banyuwangi

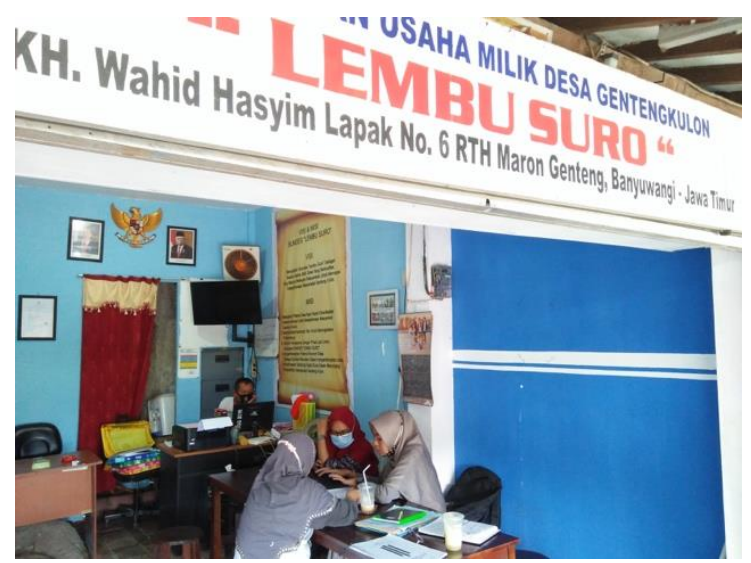

Gambar 1. Kunjungan awal kegiatan pengamatan masalah di kantor BUMDes Lembu Suro.

Adapun kegiatan audit dilaksanakan pada tanggal 12 bulan Maret tahun 2021. Kegiatan diawali dengan pembukaan dari Kepala Desa Genteng Kulon. Setelah itu, kegiatan audit dilakukan. Kegiatan audit membutuhkan kehadiran dan partisipasi semua pengurus BUMDes Lembu Suro agar data yang diberikan cukup. BUMDes Lembu Suro tersebut mempunyai aset yang cukup banyak untuk dikelola. Aset tersebut bisa dikategorikan sebagai unit usaha karena mempunyai manajer yang berbeda. Adapun daftar aset BUMDes Lembu Suro dapat dilihat pada Tabel 1.

Tabel 1. Daftar asset BUMDes Lembu Suro, Genteng Kulon.

\begin{tabular}{clcc}
\hline No. & Aset Usaha & & Jumlah \\
\hline 1 & Ruko moinan & 10 \\
2 & Lintasan motor mainan & 1 \\
& $\begin{array}{l}\text { anak-anak } \\
3\end{array}$ & Lahan parkir di sekitar & 1 \\
& taman & & 3 \\
4 & Toilet umum & & 3 \\
5 & Lahan pedagang kaki lima & 12 \\
\hline
\end{tabular}

Aset usaha yang dikelola BUMDes bernilai cukup tinggi. Transaksi yang dilakukan oleh BUMDes dengan warga yang menyewa dicatat cukup rinci dan teliti. Akan tetapi, pencatatan setiap transaksi tidak terstandar. Beberapa unit usaha dicatat dalam buku yang sama, namun ada yang dicatat pada buku khusus. Unit usaha yang memiliki buku pencatatan tersendiri yaitu unit usaha tempat parker. Adapun agar proses audit keuangan berjalan lancar, BUMDes Lembu Suro wajib menyediakan informasi atau dokumen yang ada pada Tabel 2 .

Tabel 2. Dokumen wajib Pembukuan Sederhana BUMDes Lembu Suro, Genteng Kulon.

\begin{tabular}{cl}
\hline No. & Kategori Dokumen \\
\hline 1 & Laporan Posisi Keuangan \\
2 & Laporan Aktivitas \\
3 & Laporan Rugi/Laba \\
\hline
\end{tabular}

Pengamatan dokumen catatan
keuangan dilakukan bersamaan dengan
diskusi mendalam dengan Bendahara dan
Sekretaris BUMDes (Gambar 2). Kegiatan
diskusi mendalam juga dilakukan kepada
seluruh pengurus BUMDes untuk memperjelas
transaksi yang masih bermasalah dan untuk
mengetahui kondisi terkini permasalahan
pencatatan keuangan yang dilakukan oleh
BUMDes Lembu Suro.

Pengamatan dokumen catatan keuangan dilakukan bersamaan dengan diskusi mendalam dengan Bendahara dan Sekretaris BUMDes (Gambar 2). Kegiatan diskusi mendalam juga dilakukan kepada seluruh pengurus BUMDes untuk memperjelas transaksi yang masih bermasalah dan untuk mondisi terkini permasalahan BUMDes Lembu Suro. 


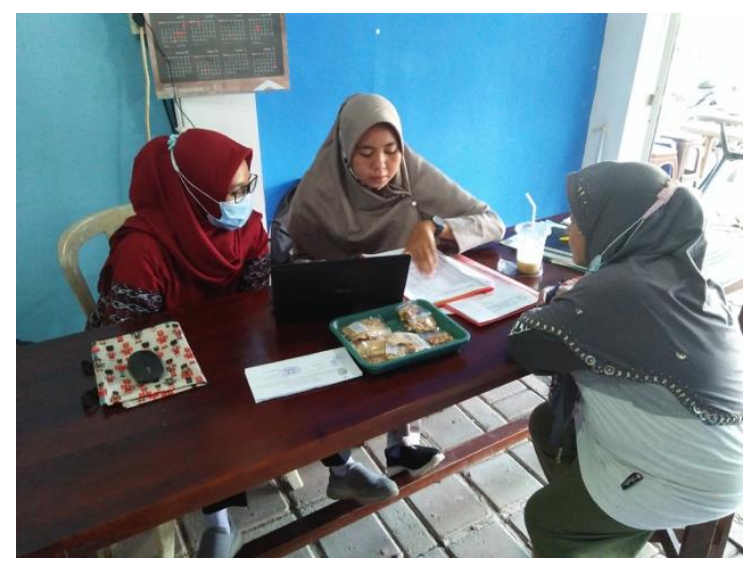

Gambar 2. Proses pengamatan dan audit pada laporan keuangan BUMDes oleh dosen Agribisnis ITBM Banyuwangi Bersama Bendahara dan Sekretaris BUMDes Lembu Suro.

Pengamatan dan audit catatan keuangan disesuaikan dengan laporan keuangan BUMDes untuk Kepala Desa dan BPD (Badan Perwakilan Desa) yang dilakukan pada setiap bulan. Contoh dokumen laporan keuangan per bulan dari BUMDes Lembu Suro ada pada Gambar 3. Proses pengamatan terhadap beberapa jenis dokumen keuangan cukup sulit dilakukan akibat standar pencatatan yang tidak seragam. Selain itu, banyak nama yang berbeda ketika mencatat transaksi pada buku transaksi dengan nama unit transaksi yang ada di laporan keuangan. Oleh karena itu, kehadiran seluruh pengurus BUMDes sangat membantu proses audit keuangan.

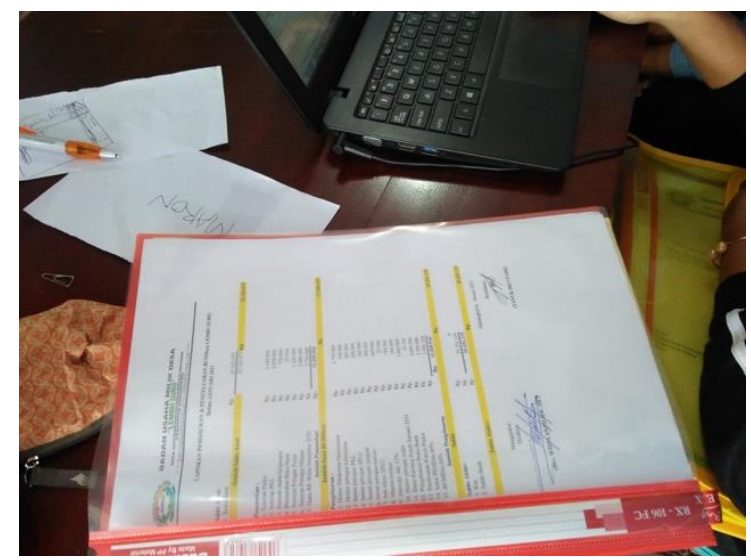

Gambar 3. Dokumen laporan keuangan per bulan BUMDes Lembu Suro, Genteng Kulon.

Berdasarkan pengamatan yang dilakukan, dapat disimpulkan bahwa BUMDes Lembu Suro telah melakukan penyusunan yang bertanggung jawab. Seluruh jenis kegiatan terdokumentasi dan setiap transaksi keluar atau masuk dapat dilihat melalui bukti nota dan kwitansi. Akan tetapi, dokumentasi yang telah dilakukan masih tergolong belum rapi, sehingga cukup sulit untuk melihat pencatatan yang konsisten dan mudah untuk dipahami oleh pihak di luar manajemen.

Berdasarkan diskusi dengan manajemen BUMDes, format pelaporan keuangan tersebut merupakan format yang telah dilakukan dari sejak dulu dan belum pernah ada pelatihan pembukuan dari manapun. Format yang disajikan tersebut masih mempunyai banyak kekurangan, sehingga perlu diperbaiki agar menjadi lebih mudah dibaca.

Kelemahan pelaporan keuangan yang selanjutnya adalah tentang keberadaan jurnal umum. Jurnal umum merupakan catatan transaksi secara umum dengan komponen yang dibedakan menjadi dua kategori yaitu transaksi masuk atau debet, dan transaksi keluar atau dinamakan kredit. Dari jurnal umum ini akan memberi kemudahan dalam melihat komponen transaksi.

Proses audit keuangan juga menjadi proses pengamatan mendalam kondisi keuangan BUMDes. Dari proses tersebut, ditemukan beberapa kelemahan dalam sistem pencatatan keuangan BUMDes. Berdasarkan temuan-temuan tersebut, BUMDes dapat segera memperbaiki dengan pendampingan dan pelatihan dari Agribisnis ITBM Banyuwangi. Adapun temuan berbagai kelemahan sistem pencatatan keuangan BUMDes Lembu Suro, dapat dilihat dalam Tabel 3.

Tabel 3. Temuan hasil pengamatan dan audit pembukuan BUMDes Lembu Suro, Genteng Kulon.

\begin{tabular}{|c|c|}
\hline No. & Kelemahan yang ditemukan \\
\hline 1 & $\begin{array}{l}\text { Pencatatan transaksi keuangan dari } \\
\text { bendahara belum dilakukan dengan } \\
\text { rapi, sehingga sangat sulit untuk } \\
\text { melacak bukti transaksi. }\end{array}$ \\
\hline 2 & Belum adanya jurnal umum. \\
\hline 3 & $\begin{array}{l}\text { Belum adanya buku besar yang } \\
\text { mencatat masing-masing akun } \\
\text { transaksi sehingga akan lebih sulit } \\
\text { membuat laporan laba rugi. }\end{array}$ \\
\hline 4 & $\begin{array}{l}\text { Terdapat beberapa penamaan item } \\
\text { pemasukan dan pengeluaran yang } \\
\text { tidak konsisten. }\end{array}$ \\
\hline 5 & $\begin{array}{l}\text { Pada item pengeluaran, terdapat } \\
\text { transaksi penarikan tunai melalui bank } \\
\text { untuk kepentingan yang beragam } \\
\text { namun tidak dijelaskan detail } \\
\text { peruntukannya. }\end{array}$ \\
\hline
\end{tabular}

Hasil temuan pada Tabel 3 segera disosialisasikan kepada seluruh anggota pengurus BUMDes. Hal tersebut diperlukan agar setiap anggota memahami dan bisa segera memperbaiki cara pencatatan 
keuangan yang dilakukan. Sosialisasi temuan tersebut dilanjutkan dengan pemberian materi tentang pembukuan keuangan sederhana yang lebih baik. Dengan mencocokkan hasil temuan, maka contohnya bisa langsung dapat dilihat. Proses pemberian materi pembukuan sederhana menggunakan slide presentasi di laptop dan dihadiri oleh seluruh anggota pengurus BUMDes Lembu Suro (Gambar 4).

Materi pembukuan berisi tentang sistem pencatatan sederhana yang baik dan berbagai contohnya. Kemudian juga contoh sistem pembukuan yang akan dibangun pada perangkat lunak Microsoft Excel. Mengetahui bahwa salah satu pengelola BUMDes adalah seorang pemuda, maka penggunaan Microsoft Excel akan lebih cepat untuk dipelajari. Selain itu, menggunakan bantuan perangkat lunak Microsoft Excel akan mempermudah pencatatan dan akan lebih konsisten terhadap hasil pembukuan. Hal itu dijelaskan oleh Ibrahim dkk (2018) bahwa pelayanan BUMDes kepada masyarakat dapat meningkat dengan adanya komputerisasi pada kegiatan BUMDes. Oleh karena itu, proses pendampingan manajemen keuangan dengan melakukan pengamatan dan audit eksternal dari Agribisnis ITBM Banyuwangi dapat memberikan edukasi bagi BUMDes juga sebagai bahan informasi untuk mengembangkan sistem keuangan BUMDes dengan lebih baik.

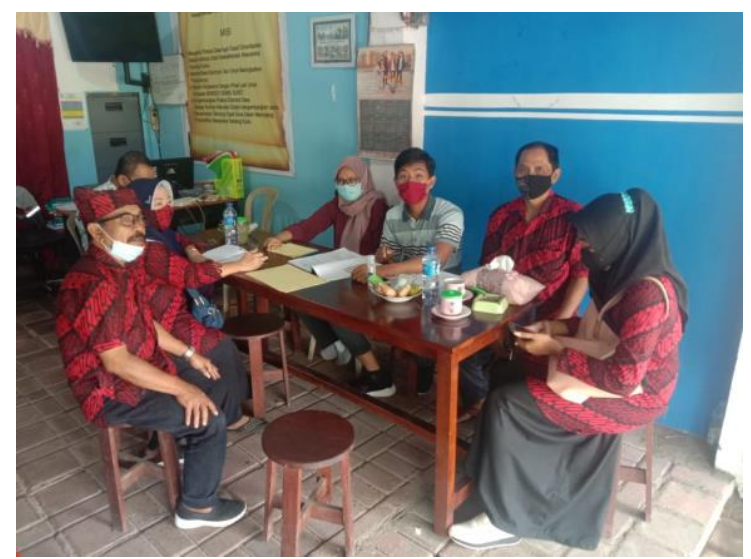

Gambar 2. Sosialisasi temuan dan pemberian materi pembukuan sederhana kepada BUMDes Lembu Suro, Genteng Kulon.

\section{SIMPULAN DAN SARAN Simpulan}

Lembaga BUMDes Lembu Suro, Desa Genteng Kulon, merupakan lembaga yang mempunyai peran penting untuk kebangkitan perekonomian masyarakat Desa Genteng Kulon. Untuk menjadi lembaga ekonomi dengan fungsi yang optimal, maka manajemen BUMDes haruslah juga optimal. Salah satu manajemen yang perlu diperbaiki adalah manajemen keuangan. Hasil diskusi secara mendalam dan audit eksternal dari Prodi Agribisnis ITBM Banyuwangi menemukan berbagai kelemahan. Hasil tersebut menjadi dasar informasi untuk melakukan perbaikan. Pemberian contoh pembukuan sederhana telah diikuti oleh pihak manajemen BUMDes dengan harapan ilmu yang didapat akan menjadi referensi kemajuan BUMDes Lembu Suro.

\section{Saran}

Setelah melakukan diskusi dan audit eksternal terkait dengan manajemen keuangan BUMDes, Prodi Agribisnis menyarankan untuk mengadakan pelatihan pembukuan secara lebih dalam. Pelatihan tersebut bisa diikuti oleh para pemangku kepentingan, agar para pemangku kepentingan juga mampu melihat struktur pembukuan yang lebih baik.

\section{UCAPAN TERIMAKASIH}

Ucapan terima kasih kami sampaikan kepada pihak Kampus ITBM Banyuwangi terkhusus kepada Lembaga Penelitian dan Pengabdian Masyarakat atas dukungannya pada kegiatan ini. Ucapan terima kasih juga kami sampaikan kepada lembaga Desa Genteng Kulon atas kerjasamanya dalam menyajikan permasalahan dan data sebaik mungkin agar pengabdian ini dapat dilakukan dengan benar.

\section{DAFTAR RUJUKAN}

[Kemendes] Kementerian Desa, Pembangunan Daerah Tertinggal dan Transmigrasi. (2021). BUMDes jadi kunci pemulihan ekonomi tingkat desa. Kemendes PDTT.

https://kemendesa.go.id/berita/view/de til/3776/BUMDes-jadi-kuncipemulihan-ekonomi-tingkat-desa

[Kemenkopukm] Kementerian Koperasi dan Usaha Kecil dan Menengah. (2021). Perkembangan data usaha mikro, kecil, menengah (UMKM) dan usaha besar (UB) tahun 2018 - 2019. Kemenkopukm.

https://kemenkopukm.go.id/uploads/la poran/1617162002_SANDINGAN_DA TA_UMKM_2018-2019.pdf

Asti, A., \& Cholid, I. (2018). Persepsi Dan Partisipasi Pemerintah Desa Dalam Perencanaan Pengembangan Bumdes Di Kecamatan Kendawangan. Jurnal Agribisnis Indonesia, 6(1), 1. https://doi.org/10.29244/jai.2018.6.1.114.

Irawati, D., \& Martanti, D. E. (2017). Transparasi Pengelolaan Laporan Keuangan BUMDes terhadap Pelaporan Aset 
Desa (Studi Fenomenologi Pada BUMDes Desa Karangbendo Kec Ponggok Kab Blitar). Prosiding Seminar Nasional Dan Call For Paper Ekonomi Dan Bisnis, 2017, 41-51.

Nainggolan, E, U, P. (2020). Ekonomi bangkit, ekonomi Indonesia terungkit. Kementerian Keuangan: Artikel DJKN. https://www.djkn.kemenkeu.go.id/artik el/baca/13317/UMKM-Bangkit-

Ekonomi-Indonesia-Terungkit.html.

Ibrahim, I., Mas,ad, M., Kamaluddin, K., \& Djunaidi, A. (2018). Peningkatan Kualitas Pelayanan Badan Usaha Milik Desa Melalui Pelatihan Administrasi Program Simpan Pinjam Di Selebung Batukliang Lombok Tengah. SELAPARANG Jurnal Pengabdian Masyarakat Berkemajuan, 1(2), 13. https://doi.org/10.31764/jpmb.v1i2.457.

Ibrahim, I., \& Sutarna, I. T. (2018). Pengelolaan Badan Usaha Milik Desa Dalam Meningkatkan Kesejahteraan Masyarakat Perdesaan Kawasan Pertambangan Emas Di Kabupaten Sumbawa Barat. Tataloka, 20(3), 309316.

https://doi.org/10.14710/tataloka.20.3. 309-316. 